\title{
Decisions for dummies
}

$\mathrm{C}$ hronic ditherers take note: e-help has arrived. iShould, a decisionmaking application available on the social networking website Facebook has been launched by Dr. A O'Connor and her team at the Ottawa Health Research Institute in Ontario.

The program is based on the decisionaid concepts used in health care and provides Facebook users, the most frequent of whom are under 16 years of age, with a framework for rationally making everyday life choices. iShould systematically assesses a user's basic comprehension of the problem at hand, determines the user's inherent values and then provides resolution after consultation with friends and family members.

Similar concepts have been successfully implemented in numerous medical settings. The Riverside Orthopedics Clinic in Ottawa dramatically improved efficiency by using a decision aid that leads patients through the consent process. Patients awaiting joint replacements view a video, answer a series of structured questions, then meet with physicians to discuss specific concerns. Employing this decision aid reduced the need for follow-up visits by approximately $50 \%$. Numerous other projects for education and health decision-making are currently underway. Nursing students at the University of Ottawa use decision aids to help determine the best location for starting their careers. Dr. Margaret Lawson and the Children's Hospital of Eastern Ontario are piloting a decision support program for pediatric patients and their families.

iShould has been online for only a month, but already has registered 263 users; 103 are considered "active" users. To date, decision support has been requested for questions ranging from getting a family pet to choosing a high school to addressing health-related concerns.

Ottawa researchers hope to provide youth with a structured means of making and sharing decisions that may

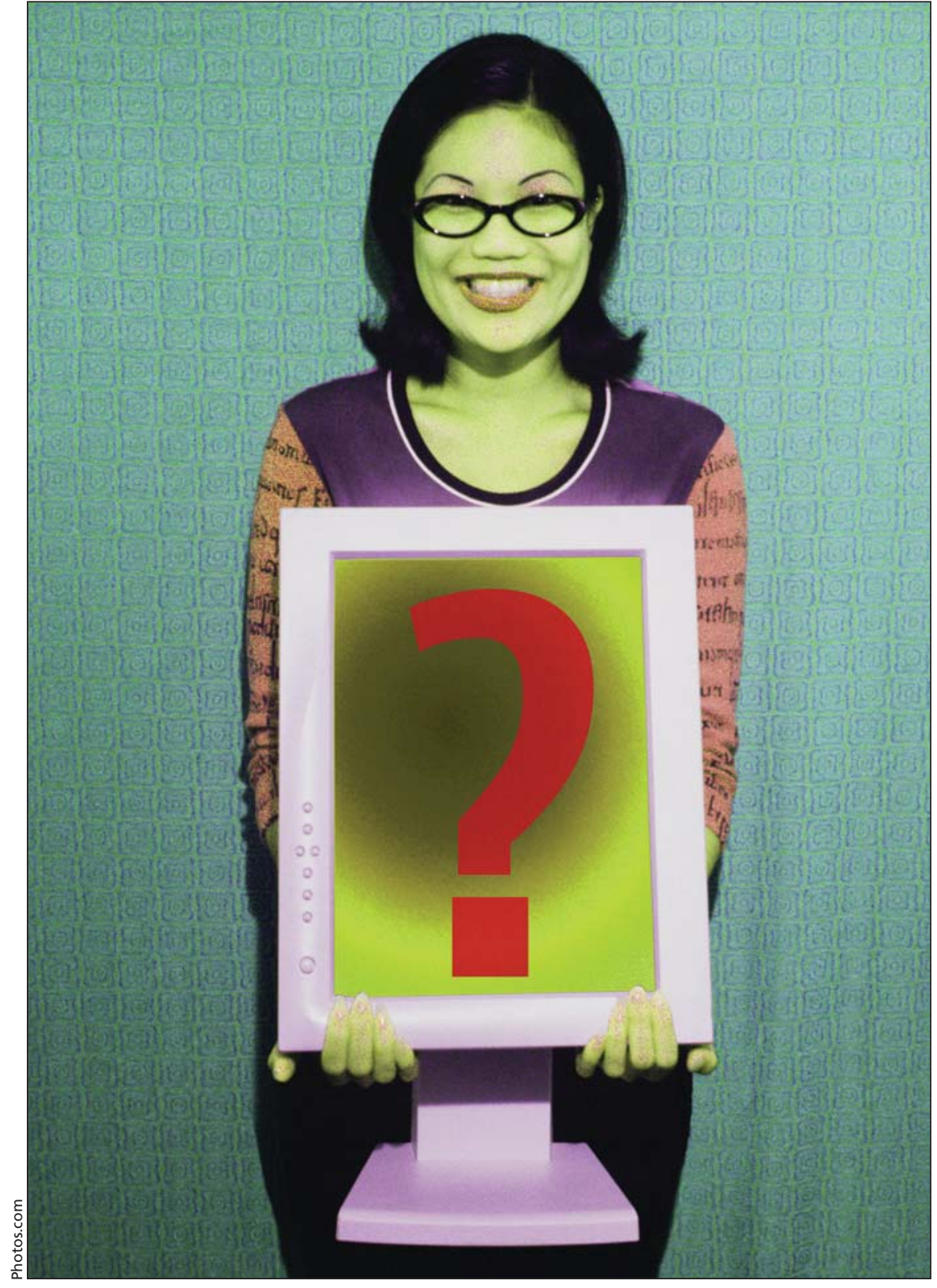

A University of Ottawa team says young patients should use online social networking to resolve their medical confusion.

prove helpful during important moments of life transition. It may help young people become healthier patients by developing a base of decision-making skills which can be drawn upon when they are faced with future med- ical problems. Dr. O'Connor says that such models promise physicians "more efficient, better prepared patients." Elizabeth Wilcox, Toronto, Ont.

DOI:10.1503/cmaj.091274 